\title{
How Job Autonomy Promotes Employee's Sustainable Development? A Moderated Mediation Model
}

\author{
Qiwei Zhou ${ }^{1}$, Qian $\mathrm{Li}^{2, *}$ and Shiyang Gong ${ }^{3}$ \\ 1 School of Economics and Management, Beijing University of Chemical Technology, Beijing 100029, China; \\ zhouqiwei1105@163.com \\ 2 International Business School, Beijing Foreign Studies University, Beijing 100089, China \\ 3 Business School, University of International Business and Economics, Beijing 100029, China; \\ gongshiyang@uibe.edu.cn \\ * Correspondence: liq@bfsu.edu.cn
}

Received: 16 October 2019; Accepted: 12 November 2019; Published: 15 November 2019

check for updates

\begin{abstract}
In the rapidly changing business world, improving employee's self-development level is of great importance for organizations to pursue sustainable development. The purpose of this study is to examine how and when job autonomy promotes employee's self-development. Drawing from self-determination theory, we examined the effect of job autonomy on employee's self-development, and the mediation role of intrinsic motivation in this relationship. Moreover, we argued that team connectivity strengthened the relationship between job autonomy and intrinsic motivation, and further moderated the indirect effect of job autonomy and self-employment via intrinsic motivation. Using a two-wave panel design, we collected data from a sample of 473 employees in China. The results indicated that job autonomy predicted employee's self-development, and employee's intrinsic motivation fully mediated this relationship. Team connectivity positively moderated the relationship between job autonomy and intrinsic motivation, and further moderated the mediation effect of intrinsic motivation. The theoretical and practical implications of this research are discussed along with the limitations and further research directions.
\end{abstract}

Keywords: organization sustainable development; self-development; job autonomy; intrinsic motivation; team connectivity

\section{Introduction}

In the rapidly changing business world, employee's up-to-date knowledge and continuous learning capability are enormously important for organizations to develop and even to survive. Therefore, organizations provide employees with various training programs for the purpose of leveraging their competence [1]. According to the latest statistics of 2018, U.S. companies have invested 160 billion dollars in staff training and education, while the cost reached 356 billion dollars world-wide. However, these investments have not yielded desired returns. It is not only because organizational training proves to be costly. Organizations are facing increasing pressure to lower the costs of training programs. Also, the effect of training remains doubtful. When employees are not internally motivated, many of them would retake the old ways of doing things once the training ended.

Accordingly, to cope with these new challenges, more attention has been paid to promoting employee's self-development [2]. Self-development refers to seeking and using feedback, setting development goals, engaging in developmental activities, and tracking progress on one's own [3]. The intention of self-development motivates employees to set and achieve goals for themselves in the next stage to meet the new changes at workplace, and to make improvements voluntarily. Prior studies have shown that employees' self-development can not only decrease organizational training costs, bring 
direct economic benefits [4], but also improve employees' levels of job satisfaction and organizational commitment [5]. Moreover, as the idea of sustainability develops, the understanding of sustainability in organizational management goes beyond the context of a sustained environmental concept to some extent. Sustainable development in organizations also indicates a long-lasting management ideas and resources, not only environmentally, but also mentally and economically [6]. According to Ehnert [7], "sustainable human resource management in organization is the pattern of planned or emerging human resource strategies and practices intended to enable organizational goal achievement while simultaneously reproducing the human resource base over a long-lasting time" (p.74). Therefore, it is reasonable to infer that promoting employee's self-development is conducive to organization sustainable development in a general way. Employees are valuable resources to promote the sustainable development of organizations. If employees could continuously update their knowledge and improve themselves, it means that the knowledge base and human resource base of the organizations are always refreshed and updated, which are beneficial to the organization survival and development in the highly competitive market. Therefore, it is of great theoretical and practical significance to further discuss what and how to promote employees' self-development.

Previous research mainly explored the predictors of employee's self-development from two perspectives: Individual and contextual. As for individual factors, literature has found that employee's personality, such as self-efficacy, openness to experience, conscientiousness, proactive personality, and motivation, such as learning goal orientation, are positively related to employee's self-development [5, 8-13]. As for contextual antecedents, early research has demonstrated that organizational support, a series of supportive organizational policies, environmental factors [11-14] and feedback system [15] would facilitate individual's engagement in self-development activities.

Despite the current progress in literature of self-development, we notice that few studies have paid attention to the characteristics of job design. According to the Job Diagnostic Model, features of job design may significantly influence employees' internal working motivations and their following behaviors $[16,17]$. Therefore, in this research, we will expand the antecedents of self-development from the perspective of job design. To the best of our knowledge, research on the relationship between job design and employee's self-development was limited. Accordingly, we will focus on one of the most important characteristics of job design-job autonomy, the degree of freedom, discretion and independence an employee could have when allocating time, deciding working methods, and other aspects at work $[16,17]$. Current studies have confirmed that job autonomy would extend employees' role breadth [18], improve intrinsic motivation, organizational commitment, job satisfaction, job performance, and reduce absence, stress and burnout $[19,20]$. When employees are endowed with high autonomy, they would be highly motived and are prone to take on more responsibilities.

Hence, we draw on self-determination theory to explore the relationship between job autonomy and self-development. Self-determination theory states that individuals have a basic desire to determine their own behaviors [21-26]. When employees feel they have the control over their behaviors, or they could engage in certain tasks discretionally, they would be highly motivated and are more willing to work. As a comprehensive framework, self-determination theory answers the question of how to unlock a person's full potential. It stresses individuals' inherent tendencies toward growth and self-actualization through the satisfaction of basic psychological needs for autonomy, competence, and relatedness. Utilizing this theory as framework, our study attests to its potential for fostering sustained behavior change and wellness, and tests its generalizability in eastern culture context. Specifically, drawing from self-determination theory, we argue that job autonomy could satisfy an individual's desire of self-determination, thus increasing their motivation to learn new knowledge and skills. We predict that job autonomy will positively influence individual's self-development, and intrinsic motivation is the mediator in this relationship [27]. In addition, since external factors could contribute to cultivating the workplace environment as determining, we propose that team connectivity, indicating the open relationships encouraging generativity among team members which enable employees to consider the diverse influences from others as learning and growing opportunities [28,29], may strengthen the 
relationship between job autonomy and intrinsic motivation, and further moderates the indirect effect of job autonomy and self-employment via intrinsic motivation. Overall, our research contributes to the literature in three ways. First, we introduced the job-design perspective to self-development field and examined the predicting role of job autonomy on self-development. Second, we revealed the psychological mechanism linking job autonomy and self-development. Third, we investigated the contextual factor of team connectivity, which plays a moderating role in the relationship between job autonomy and self-development.

\section{Theory and Hypotheses}

\subsection{Job Autonomy and Employee Self-Development}

Job autonomy refers to the degree of freedom, discretion and independence an employee has when deciding time division, working methods and other aspects at work [16,17]. In a high-autonomous job, employees can decide what, how, and when to conduct their assigned tasks. Previous research has shown that high job autonomy could give employees time, energy, and freedom to engage in certain behaviors, thereby improving their willingness and motivation to develop and plan for the further $[16,17,19,20]$.

According to the self-determination theory, it states that when individuals feel they have control over their behaviors, or they can engage in certain jobs or tasks in discretional manners, they will be highly motivated to work hard, and always lead to positive job attitudes and higher job efficiency [21-26]. Research has shown that autonomy, competence, and relatedness are pivotal psychological needs ought to be fulfilled so as to create the sense of self-determining [27,30]. Among the three, autonomy plays a more fundamental role. When considering their jobs as autonomous, employees' perceptions of self-determining are enhanced, thus leading to the willingness of engaging in positive individual developmental activities [27].

Therefore, we propose that job autonomy may increase employee's self-development. Specifically, since job autonomy enables employees to allocate their time and energy in work independently, gives them the freedom to choose working approaches and to decide the frequency of interactions with other colleagues, it could predict self-development from the following aspects. First, when employees perceive that they have a higher level of autonomy and independence in deciding how to carry out their work, they may feel higher level of self-determination and perceive the job to be their own business. Accordingly, they would feel more internally motivated and be aroused of higher passion at work. They may behave more actively and come up with more ideas beneficial to their own and organization's long-term development. Second, when employees are given the high autonomy to conduct their tasks, it means that they will have more time and flexibility to decide the following steps and working procedures. It may trigger them to reflect on their past behaviors, adjust the procedures and set developmental goals to meet further requirements. Third, job autonomy allows employees to generate more ideas and thoughts to modify their work. This idea-generation and innovation process is also beneficial for employee's development in the long run. Finally, job autonomy also provides employees with more freedom and opportunities to exchange information with their colleagues. In this vein, employees would know better about the external information and the progresses others have made, which motivates them to set up higher and developmental goals for themselves and keep track of the goal attainment process. Accordingly, we hypothesize:

Hypothesis 1 (H1). Job autonomy is positively related to employee's self-development.

\subsection{Mediating Role of Intrinsic Motivation}

Motivational orientation is one of the most fundamental individual characteristics, which describes one's underlying goal and attitude towards tasks. It indicates for what reasons an individual is 
motivated to work [31]. With different motivational orientations, an employee's working attitude and performance level may be quite different [21]. Early research has demonstrated that intrinsic motivation is an important driving factor to promote individuals to learn and achieve their goals [25,27]. It will enhance employees' working engagement, performance, job satisfaction, and creativity. Employees with intrinsic motivation will be deeply involved in their tasks, strive to learn new skills, and continually improve their creativity. They often consider their work as interesting or fascinating, which will bring them happiness and satisfaction $[25,27,31]$.

Previous research has illustrated that satisfying individual's autonomous needs and letting them perceive that they have control over their work [32] (p. 8) could generate intrinsic motivation. In this study, we further argue that intrinsic motivation will be positively related to employee's self-development and mediates the relationship between job autonomy and self-development. In nature, self-development is one's implicit intention to seek feedbacks, set goals and take more actions for future progress. Consistent with this logic, we believe that when employees are intrinsically driven, they will think of the work to be their own business and be more responsible for the future development. They will take initiatives to evaluate environmental needs and predict future development trend, so that they could acquire the corresponding skills and knowledge. Also, they will actively search for feedbacks and set development-oriented goals for the long term. Thus, we propose that:

Hypothesis 2 (H2). Employee's intrinsic motivation is positively related to self-development.

In addition, according to the self-determination theory [21], we further propose that intrinsic motivation lays foundation for the mechanism through which a self-determining environment could eventually promote subsequent self-development. It is because that the influence of job autonomy on self-development basically depends on an employee's self-regulated behaviors and discretionary efforts, which is largely impacted by an employee's level of intrinsic motivation. On the basis level, intrinsic motivation determines to what extent employees can take advantage of job autonomy and make independent decisions for future development [31]. Consistent with self-determination theory, we argue that even with the same job autonomy level, employees with varied levels of intrinsic motivation will be impacted differently. It is the intrinsic motivation that determines an employee's actual level of willingness to work hard, make improvements, set and pursue developmental goals. In high-autonomy work, employees may perceive higher level of self-determination, since they are empowered with more freedom, discretion, and independence at work. Therefore, they may feel that they are working for themselves and internally motivated, hence are willing to put in more efforts and make progress in their work. In sum, we posit:

Hypothesis 3 (H3). Intrinsic motivation mediates the relationship between job autonomy and employee's self-development.

\subsection{Moderating Role of Team Connectivity}

Environmental factors can also provide employees with a self-determining perception, with which employees will have more trust and confidence towards their workplace, thus result in more positive and proactive behaviors [33]. Accordingly, as one of the most important environmental factors, team characteristics could play influential roles in shaping employees' behaviors and attitudes. In this vein, we propose that team connectivity may impact one's self-determination perception and strengthen the relationship between job autonomy and intrinsic motivation.

By definition, team connectivity means that the relationships between team members are open and encourage generativity, enabling members to treat their interactions as opportunities for growing and learning $[28,29]$. Consistent with the psychological needs one should fulfill in order to create self-determining perceptions $[27,30]$, we posit that team connectivity could help employees to see the value of learning new things, generating new ideas, and seeking opportunities to explore and 
develop. First, the high team connectivity will make the employees feel that the job is effective and they could achieve valuable goals at work [34], which fulfills an employee's psychological need of competence. Also, team connectivity implies a safe environment for employees to take risks trying new or challenging tasks, which would in turn facilitate learning and growing at work [35]. Even if they fail, the errors could be tolerated and the "trouble-makers" will be cared about. Team leader and other members will look for the underlying answers and seek for core questions in cooperative and collaborative manners. Hence, the employees may feel that they are well understood and closely related with others at work [36]. In this way, an employee's psychological need of relatedness is satisfied. Following this, we argue that in teams with high connectivity, job autonomy tend to generate more intrinsic motivation, since employees have received more competence and relatedness at work, which in turn strengths the influence of job autonomy on intrinsic motivation. On the contrary, in teams with low connectivity, employees may feel less generativity at work and thus lower their motivation and preserve their effort. Thus, we propose:

Hypothesis 4 (H4). Employee's perceived team connectivity moderates the relationship between job autonomy and intrinsic motivation such that the relationship is stronger when team connectivity is high.

\subsection{The Integrative Model}

Further, research has shown that team connectivity enables employees to see the diverse influences from other members as opportunities for learning and growth at work, which would promote learning and creativity ultimately [37]. Since these learning opportunities and cognitive diversities are also pivotal to broadening perspectives, realizing the gaps between current and ideal situations, and providing directions for goal setting, we believe that team connectivity could also enhance the indirect effect of job autonomy and self-employment. In combination, drawing from self-determination theory, the relationships predicted in Hypotheses 3 and 4 lead to the final step in our conceptual analysis: The prediction that employee's intrinsic motivation mediates the relationship between job autonomy and self-development is contingent on team connectivity (see Figure 1). Specifically, on the basis of reaching employees' autonomous psychological need, there will be a stronger mediating relationship when team connectivity is high, since the generativities and connections in teams will fulfil employees' basic psychological needs of competence and relatedness. In this way, we propose:

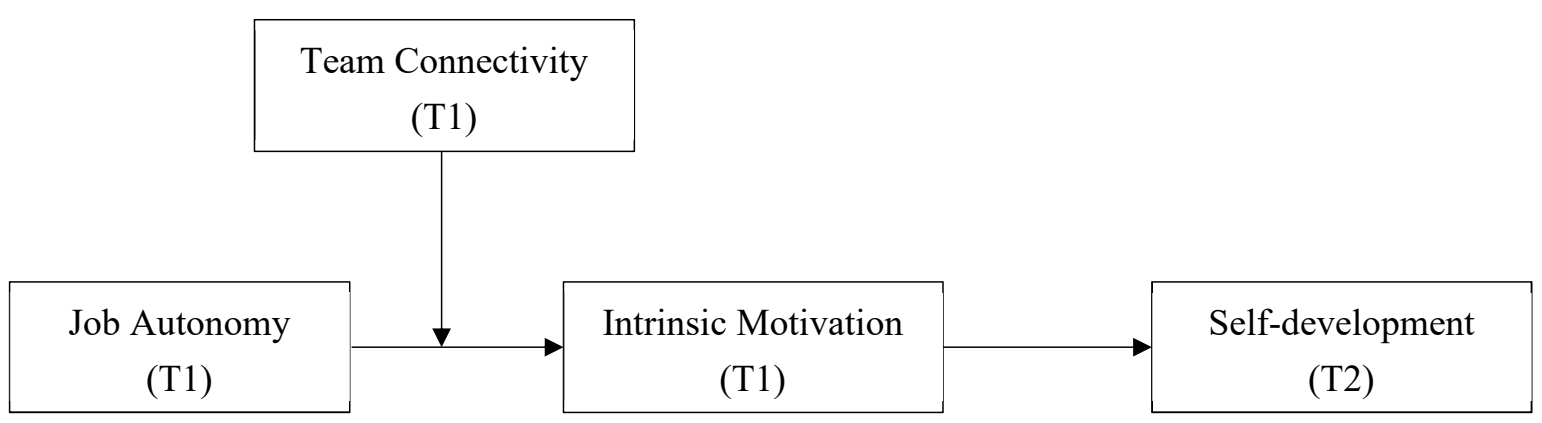

Figure 1. The theoretical model of our research. Note: T1 means the data was collected at Time 1, T2 means the data was collected at Time 2.

Hypothesis 5 (H5). Employee's perceived team connectivity moderates the indirect effect of job autonomy on employee's self-development through intrinsic motivation such that this indirect effect is stronger when team connectivity is relatively high.

Figure 1 summarized the theoretical framework. 


\section{Methodology}

\subsection{Sample and Data Collection}

Participants were recruited via wjx.cn, a reliable Chinese data collection platform similar to Qualtrics Online Sample and widely used in prior studies [38,39]. The sample size of this platform is 2.6 million, which enabled us to cover a relatively diverse sample across industries and other related job characteristics. The data collection took place in two waves and over a period of two weeks. At Time 1, our questionnaire was distributed to 648 participants via wjx.cn. All participants were current employees in various industries. They provided their demographic information and completed a survey that measures their perceived job autonomy, intrinsic motivation and perceived team connectivity. At Time 2, two weeks later, we distributed the questionnaires of self-development to the same participants. Each participant was compensated by 20 Chinese yuan for completing two surveys.

Excluding cases with missing data, we obtained a final sample of 473 participants, yielding a response rate of $73 \%$. The majority of our participants were between the ages of 26 and 35 years old $(52.6 \%)$, female $(56.9 \%)$, and college educated $(68.7 \%)$. Among them, $31.9 \%$ were entry-level employees, $39.7 \%$ were first-line managers and $25.2 \%$ were middle managers. Their average tenure in the team was 5.3 years (standard deviation $[S D]_{\text {tenure }}=5.01$ ).

\subsection{Measures}

We used 7-point scale ranging from 1 ("strongly disagree") to 7 ("strongly agree") for all substantive variables. We followed translation and back-translation procedures to translate all the items from English to Chinese [40].

Job autonomy. We measured employees' perceived level of job autonomy using a 3-item scale. This scale consisted of two items from Job Diagnostic Survey (JDS) [17] and one item from the revised JDS [41]. Participants were asked how much authority they had in their work. An example item featured "This job allows me to decide on my own how to go about doing the work." Cronbach's alpha was 0.86 .

Intrinsic motivation. We measured employees' intrinsic motivation using the 15 -item scale from Work Preference Inventory [31]. Example item is "I want my work to provide me with opportunities for increasing my knowledge and skills." Cronbach's alpha was 0.82 .

Team connectivity. Employees completed a 7-item measure of team connectivity [42]. Illustrative item is "The relationships we have encourage us to seek out new opportunities." Cronbach's alpha was 0.83 .

Self-development. We operationalized self-development using a five-item scale [15]. Illustrative item is "I have committed myself to improve my job performance in the future." Cronbach's alpha was 0.70 .

Control variables. We included following control variables because of their potential impact on employee's development [43]: gender $(0=$ female; $1=$ male), age (categorized in ten bands, $1=$ "under 20 years old", $2=$ "21 25 years old", $3=$ "26 30 years old", $4=$ "31 35 years old", $5=$ "36 40 years old", $6=$ "41 45 years old", $7=$ "46 50 years old", $8=$ "51 55 years old", $9=$ "56 60 years old", $10=$ "above 60 years old"), education level ( $1=$ middle school or below, $2=$ high school; $3=$ junior college; $4=$ undergraduate degree; $5=$ graduate degree; $6=$ doctoral degree), positions in the organization $(1=$ employee, 2 = first-line manager; $3=$ middle manager; $4=$ senior manager), and tenure in current teams (measured in years). 


\section{Results}

\subsection{Confirmatory Factor Analyses}

We conducted confirmatory factor analysis using LISREL 8.8 to test the measurement model specifying job autonomy, intrinsic motivation, team connectivity, and self-development as separate factors. The hypothesized four-factor model demonstrated better model fit $\left(\chi^{2}(387)=782.90, p<0.05\right.$; SRMR $=0.05, \mathrm{TLI}=0.90, \mathrm{CFI}=0.92, \mathrm{RMSEA}=0.05)$ than all other models (Table 1$)$. The results provided evidence of discriminant validity among these variables. Also, the one-factor model fitted the data poorly and the first factor from explanatory factor analysis only explained $24.95 \%$ variance. Therefore, we concluded that common method bias was not a major problem in this study.

Table 1. Model fit results for confirmatory factor analyses.

\begin{tabular}{|c|c|c|c|c|c|c|c|}
\hline Models & $x^{2}$ & $d f$ & $\Delta \chi^{2}$ & SRMR & TLI & CFI & RMSEA \\
\hline $\begin{array}{c}\text { Four-factor model: } \\
\text { The hypothesized four-factor model } \\
\text { Three-factor model: }\end{array}$ & 782.90 & 387 & - & 0.05 & 0.90 & 0.92 & 0.05 \\
\hline $\begin{array}{c}\text { Combining job autonomy and intrinsic } \\
\text { motivation }\end{array}$ & 1495.97 & 390 & 713.07 & 0.07 & 0.78 & 0.81 & 0.08 \\
\hline $\begin{array}{l}\text { Combining intrinsic motivation and } \\
\text { self-development }\end{array}$ & 946.95 & 390 & 164.05 & 0.06 & 0.88 & 0.89 & 0.06 \\
\hline $\begin{array}{c}\text { Combining intrinsic motivation and team } \\
\text { connectivity }\end{array}$ & 1145.90 & 390 & 363.00 & 0.07 & 0.84 & 0.86 & 0.06 \\
\hline $\begin{array}{l}\text { Two-factor model: } \\
\text { Combining job autonomy, intrinsic } \\
\text { motivation and team connectivity }\end{array}$ & 1649.31 & 392 & 866.41 & 0.07 & 0.74 & 0.76 & 0.08 \\
\hline $\begin{array}{l}\text { Combining job autonomy, intrinsic } \\
\text { motivation and self-development }\end{array}$ & 1642.80 & 392 & 859.9 & 0.07 & 0.75 & 0.77 & 0.08 \\
\hline $\begin{array}{l}\text { One-factor model: } \\
\text { Combining all variables }\end{array}$ & 1862.37 & 393 & 1079.47 & 0.08 & 0.70 & 0.73 & 0.09 \\
\hline
\end{tabular}

Notes: $\Delta \chi^{2}$ was compared with the hypothesized four-factor model (hypothesized model). Abbreviations: CFI = comparative fit index; RMSEA = root-mean-square error of approximation; SRMR = standardized root-mean-square residual; TLI = Tucker-Lewis index.

\subsection{Descriptive Statistics}

Table 2 presents descriptive statistics, including means, standard deviations, correlations, and reliabilities of the focal variables.

Table 2. Means, standard deviations, correlations, reliabilities, and collection schedule among studied variables.

\begin{tabular}{|c|c|c|c|c|c|c|c|c|c|c|c|}
\hline Variables & Mean & $S D$ & 1 & 2 & 3 & 4 & 5 & 6 & 7 & 8 & 9 \\
\hline 1. Gender. & 0.43 & 0.50 & - & & & & & & & & \\
\hline 2. Age & 3.88 & 1.59 & $0.13^{* *}$ & - & & & & & & & \\
\hline 3. Education level & 3.90 & 0.73 & 0.04 & $-0.22 * *$ & - & & & & & & \\
\hline 4. Position level & 2.00 & 0.84 & $0.29 * *$ & $0.39 * *$ & $0.20^{* *}$ & - & & & & & \\
\hline 5. Tenure & 5.30 & 5.01 & 0.07 & $0.64^{* *}$ & $-0.17^{* *}$ & $0.27^{* *}$ & - & & & & \\
\hline 6. Job autonomy (T1) & 4.96 & 1.21 & $0.11 *$ & $0.14^{* *}$ & 0.08 & $0.30^{* *}$ & $0.11 *$ & 0.86 & & & \\
\hline 7. Intrinsic motivation (T1) & 5.25 & 0.65 & -0.05 & -0.04 & 0.06 & $0.13^{* *}$ & -0.05 & $0.40^{* *}$ & 0.82 & & \\
\hline 8. Team connectivity (T1) & 5.34 & 0.82 & -0.01 & -0.07 & $0.11 *$ & $0.12 * *$ & 0.00 & $0.50^{* *}$ & $0.51^{* *}$ & 0.83 & \\
\hline 9. Self-development (T2) & 5.83 & 0.68 & $-0.11 *$ & -0.03 & $0.16^{* *}$ & 0.06 & -0.05 & $0.24^{* *}$ & $0.45^{* *}$ & $0.45^{* *}$ & 0.70 \\
\hline
\end{tabular}

Notes: $\mathrm{N}=473, \mathrm{SD}=$ standard deviation. Cronbach's alpha values for the variables are shown in italics along the diagonal. T1 means the data was collected at Time 1, T2 means the data was collected at Time 2 . Gender: $0=$ female, $1=$ male; age: $1=$ under 20 years old, $2=21 \sim 25$ years old, $3=26 \sim 30$ years old, $4=31 \sim 35$ years old, $5=36 \sim 40$ years old, $6=41 \sim 45$ years old, $7=46 \sim 50$ years old, $8=51 \sim 55$ years old, $9=56 \sim 60$ years old, $10=$ above 60 years old; Education level: 1 = middle school or below, 2 = high school, $3=$ junior college, $4=$ undergraduate degree, $5=$ graduate degree, $6=$ doctoral degree; Position level: $1=$ employee, $2=$ first-line manager, $3=$ middle manager, $4=$ senior manager; Tenure in teams: measured in years. ${ }^{*} p<0.05,{ }^{* *} p<0.01,{ }^{* * *} p<0.001 .1 .1$. Hypothesis Tests. 
We used hierarchical regression analysis to test our hypotheses with AMOS 24.0 (IBM Corp, Armonk, NY, USA) and SPSS 20.0. (IBM corp in Chicago, IL, USA).

Tests of main effect. Hypothesis 1 posits that job autonomy is positively related to self-development. As shown in Table 3, Model 1 is the null model that only includes control variables: age, gender, educational level, position level, and tenure in the team. The results of Model 2 indicate that after controlling for employee's demographics information, employee's perceived job autonomy level was positively associated with self-development $(b=0.13$, Standard Errors [SE] $=0.03, p<0.001$, Model 2$)$. Thus, Hypothesis 1 is supported.

Table 3. Hierarchical regression results.

\begin{tabular}{|c|c|c|c|c|}
\hline \multirow[t]{2}{*}{ Variables } & \multicolumn{3}{|c|}{ Self-Development } & \multirow{2}{*}{$\begin{array}{c}\begin{array}{c}\text { Intrinsic } \\
\text { Motivation }\end{array} \\
\text { Model } 4\end{array}$} \\
\hline & Model 1 & Model 2 & Model 3 & \\
\hline $\begin{array}{l}\text { Intercept } \\
\text { Controls }\end{array}$ & $5.27^{* * *}(0.20)$ & $4.76^{* * *}(0.22)$ & $2.88^{* * *}(0.29)$ & $5.31^{* * *}(0.17)$ \\
\hline Gender & $-0.18^{* *}(0.07)$ & $-0.19 * *(0.06)$ & $-0.13 *(0.06)$ & $-0.10 *(0.05)$ \\
\hline Age & $0.01(0.03)$ & $0.00(0.03)$ & $0.02(0.02)$ & $-0.01(0.02)$ \\
\hline Education level & $0.13^{* *}(0.05)$ & $0.13^{* *}(0.04)$ & $0.13^{* *}(0.04)$ & $-0.02(0.04)$ \\
\hline Position level & $0.06(0.04)$ & $0.01(0.04)$ & $-0.01(0.04)$ & $0.06(0.04)$ \\
\hline Tenure & $-0.01(0.01)$ & $-0.01(.01)$ & $0.00(0.01)$ & $-0.01(0.01)$ \\
\hline Independent Variable & & & & \\
\hline $\begin{array}{l}\text { Job autonomy } \\
\text { Mediator }\end{array}$ & & $0.13^{* * *}(0.03)$ & & $0.15^{* * *}(0.03)$ \\
\hline $\begin{array}{l}\text { Intrinsic motivation } \\
\text { Moderator }\end{array}$ & & & $0.47^{* * *}(0.04)$ & \\
\hline $\begin{array}{c}\text { Team connectivity } \\
\text { Interactions }\end{array}$ & & & & $0.28^{* * *}(0.03)$ \\
\hline $\begin{array}{c}\text { Job autonomy } \times \text { Team } \\
\text { connectivity }\end{array}$ & & & & $0.07^{* *}(0.02)$ \\
\hline$R^{2}$ & 0.04 & 0.10 & 0.23 & 0.31 \\
\hline Adjusted $R^{2}$ & 0.03 & 0.08 & 0.22 & 0.30 \\
\hline$\Delta R^{2}$ & - & 0.06 & 0.19 & 0.27 \\
\hline$F$ & $4.18^{* *}$ & $8.17^{* * *}$ & $23.36^{* * *}$ & $26.52^{* * *}$ \\
\hline
\end{tabular}

Notes: $N=473$. Unstandardized regression coefficients are reported (and standard errors). ${ }^{*} p<0.05,{ }^{* *} p<0.01,{ }^{* * *}$ $p<0.001$.

Hypothesis 2 argues that employee's intrinsic motivation is positively related to self-development. As displayed in Model 3 of Table 3, the relationship between employee's intrinsic motivation and self-development was significantly positive $(b=0.47, S E=0.04, p<0.001$, Model 3). Thus, Hypothesis 2 is supported.

Hypothesis 3 proposes that employee's intrinsic motivation mediates the relationship between job autonomy and self-development. We utilized PROCESS Macro for SPSS (Model 4) to examine this mediation effect [44]. With 5000 times bootstrap, after controlling for employee's demographic variables, the direct effect of job autonomy on self-development was non-significant (direct effect $=0.04$, $S E=0.03,95 \%$ Confidence Interval $[\mathrm{CI}]=[-0.01,0.09])$, while the indirect effect of job autonomy on self-development via intrinsic motivation was significant (indirect effect $=0.09, S E=0.02,95 \% \mathrm{CI}=$ $[0.07,0.13])$. Thus, intrinsic motivation fully mediates the relationship between job autonomy and self-development. Hypothesis 3 is supported.

Tests of moderation effects. Hypothesis 4 predicts that employee's perceived team connectivity moderates the relationship between job autonomy and intrinsic motivation. We tested this hypothesis using hierarchical regression and simple slopes analysis. We first mean-centered job autonomy and team connectivity to create the interaction term [45]. As displayed in Model 4 of Table 3, the interaction between job autonomy and team connectivity predicting intrinsic motivation is significant $(b=0.07, S E$ $=0.02, p<0.01$ ). In order to interpret the results, we followed Aiken and West's [46] procedures to plot the interactions between autonomy and team connectivity at their two conditional values (at one 
standard deviation above and below the mean) in Figure 2. Results from simple slope analyses show that, the positive effect of job autonomy on intrinsic motivation is stronger when team connectivity is high (simple slope $=0.21, S E=0.03, p<0.001$ ), and is weaker but still positively significant when team connectivity is low (simple slope $=0.10, S E=0.03, p<0.01$ ). Therefore, Hypothesis 4 is supported.

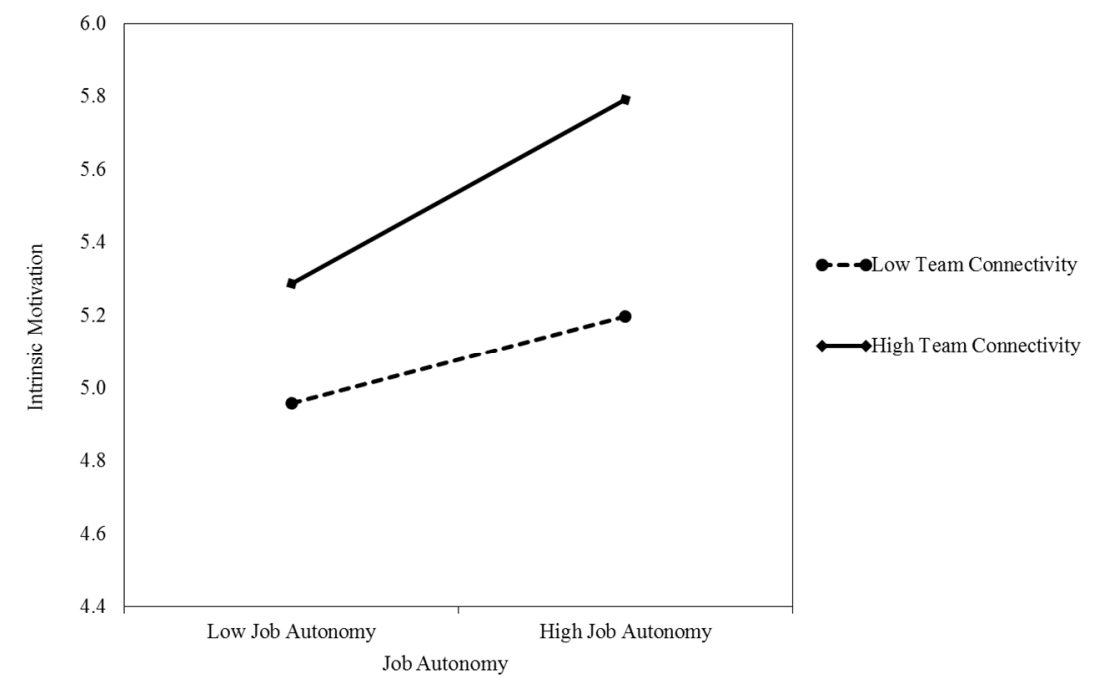

Figure 2. Interactive effects of job autonomy and team connectivity on intrinsic motivation.

Test of conditional indirect effect. In Hypothesis 5, we posit that employee's perceived team connectivity moderates the effect of job autonomy on employee self-development through intrinsic motivation such that this indirect effect is stronger when team connectivity is high. Utilizing PROCESS Macro for SPSS (Model 7) [44] we tested the conditional indirect effect by conducting a moderated path analysis using 5000 bootstrap samples for construct $95 \%$ bias-corrected confidence intervals surrounding our estimate of the indirect effect of job autonomy through intrinsic motivation [47]. Results in Table 4 indicate that, the conditional indirect effect of job autonomy on self-development through intrinsic motivation is significantly positive and stronger for employees with higher team connectivity (indirect effect $=0.08, S E=0.02,95 \% \mathrm{CI}=[0.0487,0.1197]$ ), but weaker for those with lower team connectivity (indirect effect $=0.03, S E=0.01,95 \% \mathrm{CI}=[0.0019,0.0582]$ ). Overall, the differences in the indirect effects of intrinsic motivation at high and low levels of team connectivity were significant for self-development $(\Delta$ indirect effect $=0.05)$. Hence, Hypothesis 5 is supported.

Table 4. Results of conditional indirect effect.

\begin{tabular}{|c|c|c|c|c|}
\hline \multicolumn{5}{|c|}{ Conditional Indirect Effects with Bootstrap Method (5000 Times) } \\
\hline Moderator: Team Connectivity & Effect & SE & Lower Level CI & Upper Level CI \\
\hline-1 s.d. $(4.52)$ & 0.03 & 0.01 & 0.0019 & 0.0582 \\
\hline+1 s.d. $(6.16)$ & 0.08 & 0.02 & 0.0487 & 0.1197 \\
\hline \multicolumn{5}{|c|}{ Index of Moderated Mediation } \\
\hline INDEX & \multirow{2}{*}{\multicolumn{2}{|c|}{$\begin{array}{c}\text { SE } \\
0.01\end{array}$}} & Lower level CI & Upper Level CI \\
\hline 0.03 & & & 0.0057 & 0.0548 \\
\hline
\end{tabular}

\section{Discussion}

This paper employed self-determination theory as theoretical framework and conducted a multi-time survey on employees throughout China to test hypotheses. We discussed the research question of what, how and when to promote self-development on individual level, in order to achieve organizational sustainable progress for the long run. Past research has showed that when employees feel that their actions can be determined by themselves, they will generate higher levels of 
motivation and willingness to work [21-23]. This argument laid the theoretical foundation for us to discuss the relationship between job autonomy and self-development. Our empirical results show that job autonomy has a positive effect on employee's self-development, which is fully mediated by employee's intrinsic motivation. Moreover, team connectivity moderates the relationship between job autonomy and intrinsic motivation, and further moderates the indirect effect of job autonomy on employee self-development through intrinsic motivation. Below we discuss the theoretical and practical implications, limitations, and future directions.

\subsection{Theoretical Implications}

Our research makes theoretical contributions in three ways.

First, our research sheds light on the self-development literature by identifying one strong predictor from the perspective of job design. Drawing from self-determination theory, we propose job autonomy is the potential antecedent of self-development. Prior research focused on individual characteristics [5,8-13] and supportive situational factors [11-15], little attention has been paid to job design, especially the characteristic of job autonomy. In this study, we found that job autonomy could improve one's intrinsic motivation and further promote the self-development $[16,17]$. Employees in those autonomous jobs would be more likely to conduct long-term sustainability related behaviors. Therefore, our research enriches the predictors of employee's self-development study.

Second, our research extends the relationship between job autonomy and self-development by adopting a fine-grained perspective to investigate the underlying psychological mechanism. We hypothesized and empirically proved that the effect of job autonomy on self-development was fully mediated by intrinsic motivation, indicating that no matter how much freedom and discretion an employee was endowed by job design, it is the level of intrinsic motivation that truly determines to what extent employees can take advantages of these opportunities and make independent decisions [31]. Thus, by identifying the inherent roots of self-development, our research provides with more perspectives to enhance employee's long-term sustainability by working on approaches to encourage intrinsic motivation.

Third, our research enriches the literature of self-development by exploring the contingent effect of team connectivity. According to prior research, the context in which employees are embedded also plays a crucial role in providing stimuli for employee's self-determination. In this sense, our research develops a contingent model which emphasizes the moderating effect of team connectivity in strengthening the effects of job autonomy on intrinsic motivation. Moreover, we take a further step to argue the enhancing effect on the overall positive indirect effect of job autonomy on self-development via intrinsic motivation. These findings clarify the boundary conditions under which the predicting role of job autonomy on self-development could be enhanced.

\subsection{Practical Implications}

Our research also offers vital practical implications for organizations and managers. First, our research concentrated on employee's self-development, one of the most important aspects of organization sustainable development, and verified one of its important predictors and the related underlying psychological mechanism. Hence, we provided operationalized approaches to promote the sustainable development of organizations. We suggest that, for the development of both employees and organizations, organizations should develop ways to encourage employees to prepare for new requirements in the future. For organizations, it is essential to provide development-oriented supportive resources to promote employees to take initiatives for self-improvement. For employees, they need to understand their own shortcomings in working skills, grasp the new trends of professional development, and make predictions about the changes and challenges they will encounter in order to meet the trend of the times and environmental developments.

Second, our research suggests that organizations and managers should adopt a job-autonomy design to facilitate self-development in organizations. Compared with other job characteristics [16,17], 
job autonomy is more universally applicable and easier to implement. It could not only provide employees with more freedom and discretion at work, but also fuels employees with intrinsic motivation which satisfied their basic psychological needs. Thus, this paper offers a potential direction to inspire employees to attain long-term and sustainable-oriented development in organizations.

Third, our research also indicates that generative and harmonious team member relationships could nourish employee's intrinsic motivation, and further stimulate self-development. Accordingly, managers and leaders should try to foster generative relationships in teams, which could enable employees to appreciate their jobs and tasks internally. This kind of team building approach is more efficient and more cost benefit than providing traditional organizational supportive resources (such as priced meals or large-scale training).

\subsection{Limitations and Directions for Future Research}

Although our study has many strengths, including the multi-time survey design and new perspective towards promoting organizational sustainable development, there are nevertheless limitations worth noting.

First, since our focal variables emphasized on motivation and behaviors of employees, it is more accurate to obtain the data by self-reported survey, which may result in the common method bias. In order to alleviate this problem, we not only conducted Harman's single factor test, but also followed procedures of multi-time design [48-50]. For the future research, we encourage to collect data from multi-source with multi-method to further verify our results.

Second, employees' industries, levels of job complexity, and other related job characteristics may also exert influences on job autonomy and further impact employees' self-development. Although we took a randomization data collection process to counterbalance the potential influences embedded in different jobs, it is worthwhile for future research to consider the impact of more job characteristics on influencing employees' intention to improve themselves.

Last, in our study we found that employee's gender played an important role in predicting both self-development $(b=-0.19$, SE $=0.06, p<0.01$, Model 2$)$ and intrinsic motivation $(b=-0.10, \mathrm{SE}=0.05$, $p<0.05$, Model 4). Based on current analysis, we could not draw further conclusions about whether females are more likely to be motivated by autonomous design to achieve longer developmental goals and perform better in a broader sense. Therefore, we encourage future research to further explore the gender's effect on self-development and the possible underlying mechanism

\section{Conclusions}

In the rapidly changing business world, improving employee's self-development level is of great importance for organizations to pursue sustainable development. In order to reduce organization's training cost, achieve higher employee developmental goals, and further promote organizations' sustainable development, this research explores what and how to enhance employee's self-development. Drawing from the self-determination theory, this research demonstrates that job autonomy could predict employee's self-development, and the intrinsic motivation mediates this relationship. In addition, team connectivity could enhance the positive relationship between job autonomy and intrinsic motivation, and further moderate the indirect effect of job autonomy on self-development via intrinsic motivation. The research highlights the importance of organizational sustainable development and proposes a potential approach to facilitate employee's self-development for the purpose of achieving this long-term goal.

Author Contributions: Conceptualization, Q.Z. and Q.L.; formal analysis, S.G.; writing—original draft preparation, Q.Z.; writing - review and editing, Q.L. and S.G.

Funding: This research was funded by "National Natural Science Foundation of China, grant number 71702010", "National Natural Science Foundation of China, grant number 71532003", "National Natural Science Foundation of China, grant number 71972040", "National Natural Science Foundation of China, grant number 71602033", 
"Funds for First-class Discipline Construction, grant number XK1802-5", "Funds for High-level Talent of UIBE, 18YQ05" and "China Postdoctoral Science Foundation (2019M660428)".

Conflicts of Interest: The authors declare no conflict of interest.

\section{References}

1. Lazarova, M.; Taylor, S. Boundaryless careers, social capital, and knowledge management: Implications for organizational performance. J. Organ. Behav. 2009, 30, 119-139. [CrossRef]

2. Paterson, T.A.; Luthans, F.; Jeung, W. Thriving at work: Impact of psychological capital and supervisor support. J. Organ. Behav. 2014, 35, 434-446. [CrossRef]

3. London, M.; Smither, J.W. Empowered self-development and continuous learning. Hum. Resour. Manag. 1999, 38, 3-15. [CrossRef]

4. Ellinger, A.D. The concept of self-directed learning and its implications for human resource development. Adv. Dev. Hum. Resour. 2004, 6, 158-177. [CrossRef]

5. Blau, G.; Andersson, L.; Davis, K.; Tom, D.; Arthur, H.; Karen, K.; Jim, P.; Blair, H. The relation between employee organizational and professional development activities. J. Vocat. Behav. 2008, 72, 123-142. [CrossRef]

6. App, S.; Merk, J.; Büttgen, M. Employer branding: Sustainable HRM as a competitive advantage in the market for high-quality employees. Manag. Rev. 2012, 23, 262-278. [CrossRef]

7. Ehnert, I. Sustainable Human Resource Management: A Conceptual and Exploratory Analysis from a Paradox Perspective; Physica-Verlag: Heidelberg, Germany, 2009.

8. Boyce, L.A.; Zaccaro, S.J.; Wisecarver, M.Z. Propensity for self-development of leadership attributes: Understanding, predicting, and supporting performance of leader self-development. Leadersh. Q. 2010, 21, 159-178. [CrossRef]

9. Hurtz, G.M.; Williams, K.J. Attitudinal and motivational antecedents of participation in voluntary employee development activities. J. Appl. Psychol. 2009, 94, 635-653. [CrossRef]

10. Major, D.A.; Turner, J.E.; Fletcher, T.D. Linking proactive personality and the big five to motivation to learn and development activity. J. Appl. Psychol. 2006, 91, 927-935. [CrossRef]

11. Maurer, T.J.; Weiss, E.M.; Barbeite, F.G. A model of involvement in work-related learning and development activity: The effects of individual, situational, motivational, and age variables. J. Appl. Psychol. 2003, 88, 707-724. [CrossRef]

12. Maurer, T.J.; Lippstreu, M.; Judge, T.A. Structural model of employee involvement in skill development activity: The role of individual differences. J. Vocat. Behav. 2008, 72, 336-350. [CrossRef]

13. Orvis, K.A.; Leffler, G.P. Individual and contextual factors: An interactionist approach to understanding employee self-development. Pers. Individ. Differ. 2011, 51, 172-177. [CrossRef]

14. Birdi, K.; Allan, C.; Warr, P. Correlates and perceived outcomes of 4 types of employee development activity. J. Appl. Psychol. 1997, 82, 845-857. [CrossRef] [PubMed]

15. London, M.; Larsen, H.H.; Thisted, L.N. Relationships between feedback and self-development. Group. Organ. Manag. 1999, 24, 5-27. [CrossRef]

16. Hackman, J.R.; Oldham, G.R. The Job Diagnostic Survey: An instrument for the diagnosis of jobs and the evaluation of job redesign projects. JSAS Cat. Sel. Doc. Psychol. 1974, 148.

17. Hackman, J.R.; Oldham, G.R. Development of the job diagnostic survey. J. Appl. Psychol. 1975, 60, $159-170$. [CrossRef]

18. Morgeson, F.P.; Delaney-Klinger, K.; Hemingway, M.A. The importance of job autonomy, cognitive ability, and job-related skill for predicting role breadth and job performance. J. Appl. Psychol. 2005, 90, 399-406. [CrossRef]

19. Fried, Y.; Ferris, G.R. The validity of the job characteristics model: A review and meta-analysis. Pers. Psychol. 1987, 40, 287-322. [CrossRef]

20. Humphrey, S.E.; Nahrgang, J.D.; Morgeson, F.P. Integrating motivational, social, and contextual work design features: A meta-analytic summary and theoretical extension of the work design literature. J. Appl. Psychol. 2007, 92, 1332-1356. [CrossRef]

21. Deci, E.L.; Ryan, R.M. Intrinsic Motivation and Self-Determination in Human Behavior; Plenum: New York, NY, USA, 1985. 
22. Deci, E.L.; Ryan, R.M. The support of autonomy and the control of behavior. J. Pers. Soc. Psychol. 1987, 53, 1024-1037. [CrossRef]

23. Deci, E.L.; Ryan, R.M. A motivational approach to self: Integration in personality. In Nebraska Symposium on Motivation: Perspectives on Motivation; Dienstbier, R., Ed.; University of Nebraska Press: Lincoln, NE, USA, 1991; pp. 237-288.

24. Deci, E.L.; Eghrari, H.; Patrick, B.C.; Dean, R.L. Facilitating internalization: The self-determination theory perspective. J. Pers. 1994, 62, 119-142. [CrossRef] [PubMed]

25. Gagné, M.; Deci, E.L. Self-determination theory and work motivation. J. Organ. Behav. 2005, 26, $331-362$. [CrossRef]

26. Ryan, R.M.; Deci, E.L. Intrinsic and extrinsic motivations: Classic definitions and new directions. Contemp. Educ. Psychol. 2000, 25, 54-67. [CrossRef] [PubMed]

27. Deci, E.L.; Ryan, R.M. The "what" and "why" of goal pursuits: Human needs and the self-determination of behavior. Psychol. Inq. 2000, 11, 227-268. [CrossRef]

28. Dutton, J.E.; Heaphy, E.D. The power of high-quality connections. Posit. Organ. Scholarsh. 2003, 3, $263-278$.

29. Losada, M.; Heaphy, E. The role of positivity and connectivity in the performance of business teams: A nonlinear dynamics model. Am. Behav. Sci. 2004, 47, 740-765. [CrossRef]

30. Pavot, W.; Diener, E. Happiness Experienced: The Science of Subjective Well-Being. In Oxford Handbook of Happiness; David, S., Boniwell, I., Ayers, A.C., Eds.; Oxford University Press: Oxford, UK, 2013.

31. Amabile, T.M.; Hill, K.G.; Hennessey, B.A.; Tighe, E.M. The Work Preference Inventory: Assessing intrinsic and extrinsic motivational orientations. J. Pers. Soc. Psychol. 1994, 66, 950-967. [CrossRef]

32. Ryan, R.M.; Deci, E.L. Self-regulation and the problem of human autonomy: Does psychology need choice, self-determination, and will? J. Per. 2010, 74, 1557-1586. [CrossRef]

33. Deci, E.L.; Connell, J.P.; Ryan, R.M. Self-determination in a work organization. J. Appl. Psychol. 1989, 74, 580-590. [CrossRef]

34. La Guardia, J.G.; Ryan, R.M.; Couchman, C.E.; Deci, E.L. Within-person variation in security of attachment: A self-determination theory perspective on attachment, need fulfillment, and well-being. J. Per. Soc. Psychol. 2000, 79, 367-384. [CrossRef]

35. Edmondson, A. Psychological safety and learning behavior in work teams. Adm. Sci. Q. 1999, 44, 350-383. [CrossRef]

36. Baumeister, R.F.; Leary, M.R. The need to belong: Desire for interpersonal attachments as a fundamental human motivation. Psychol. Bull. 1995, 117, 497-529. [CrossRef] [PubMed]

37. Yang, J.; Pu, B.; Guan, Z.Z. Entrepreneurial Leadership and turnover intention in startups: Mediating roles of employees' job embeddedness, job satisfaction and affective commitment. Sustainability 2019, 11, 1101. [CrossRef]

38. Buchtel, E.E.; Guan, Y.; Peng, Q.; Su, Y.J.; Sang, B.; Chen, S.X.H.; Bond, M.H. Immorality east and west: Are immoral behaviors especially harmful, or especially uncivilized? Per. Soc. Psychol. Bull. 2015, 41, 1382-1394. [CrossRef]

39. Li, C.C.; Li, D.M.; Chiu, C.Y.; Peng, S.Q. Strong brand from consumers' perspective: A cross-cultural study. J. Cross Cult. Psychol. 2019, 50, 116-129. [CrossRef]

40. Brislin, R.W. The Wording and Translation of Research Instruments; Sage Publications: Thousand Oaks, CA, USA, 1986.

41. Idaszak, J.R.; Drasgow, F. A revision of the Job Diagnostic Survey: Elimination of a measurement artifact. J. Appl. Psychol. 1987, 72, 69-74. [CrossRef]

42. Carmeli, A.; Spreitzer, G.M. Trust, connectivity, and thriving: Implications for innovative behaviors at work. J. Creat. Behav. 2009, 43, 69-191. [CrossRef]

43. Ng, T.W.H.; Feldman, D.C. The relationships of age with job attitudes: A meta-analysis. Per. Psychol. 2010, 63, 677-718. [CrossRef]

44. Hayes, A.F. Introduction to Mediation, Moderation, and Conditional Process Analysis: A Regression-Based Approach; Guilford Publications: New York, NY, USA, 2017.

45. Cohen, J.; Cohen, P.; West, S.G.; Aiken, L.S. Applied Multiple Regression/Correlation Analysis for the Behavioral Sciences, 3rd ed.; Lawrence Erlbaum Associates: Mahwah, NJ, USA, 2003.

46. Aiken, L.S.; West, S.G. Multiple Regression: Testing and Interpreting Interactions; Sage Publications: Thousand Oaks, CA, USA, 1991. 
47. Preacher, K.J.; Rucker, D.D.; Hayes, A.F. Addressing moderated mediation hypotheses: Theory, methods, and prescriptions. Multivar. Behav. Res. 2007, 42, 185-227. [CrossRef]

48. Beal, D.J. ESM 2.0: State of the Art and Future Potential of Experience Sampling Methods in Organizational Research. Annu. Rev. Organ. Psychol. Organ. Behav. 2015, 2, 383-407. [CrossRef]

49. Ohly, S.; Sonnentag, S.; Niessen, C.; Zapf, D. Diary studies in organizational research: An introduction and some practical recommendations. J. Per. Psychol. 2010, 9, 79-93. [CrossRef]

50. Podsakoff, P.M.; MacKenzie, S.B.; Podsakoff, N.P. Sources of method bias in social science research and recommendations on how to control it. Annu. Rev. Psychol. 2012, 63, 539-569. [CrossRef] [PubMed]

(C) 2019 by the authors. Licensee MDPI, Basel, Switzerland. This article is an open access article distributed under the terms and conditions of the Creative Commons Attribution (CC BY) license (http://creativecommons.org/licenses/by/4.0/). 